\title{
ELASTICITIES OF SUBSTITUTION IN REGIONAL PRODUCTION FUNCTIONS
}

\author{
Timothy L. Hunt and M. Jarvin Emerson*
}

\section{Introduction}

Depending on the complementarity or substitutability of capital (K) and labor (L) for energy (E) in production processes, higher energy prices may result in slower future growth in manufacturing. If capital and energy are complements, then higher prices for energy will dampen the demand for both energy and capital, ceteris paribus. Conversely, if energy and other inputs tend to be substitutes, then rising energy prices will stimulate the demand for both capital and labor.

The regional variation in such impacts due to differing substitution relations may be substantial. If the substitution relationships among energy, labor, and capital are different among regions, future growth patterns are likely to vary. If energy and capital are substitutes in one region but complements in another, the former will tend to grow and the latter to decline. Even moderate differences in substitution relationships between capital and energy may be manifested in growth rate differentials.

The primary objective of this paper is to explore the possibility of significant regional differences in production functions and the associated elasticities of substitution in a model which includes energy as one of the inputs. As in previous regional production function investigations, broad regional differences in agglomeration economies, technology, product mix, labor quality, and basic regional infrastructure are expected to be manifested in the parameter estimates of production functions.

Numerous investigations of regional growth have observed or analyzed nominally persistent North-South differences in factor returns, notably wages, using some form of a production

*W. E. Upjohn Institute for Employment Research, Kalamazoo, Michigan, and Kansas State University, Manhattan, respectively. function. A few examples include Gallaway [15], Bellante [3], Coelho and Ghali [10], Batra and Scully [2], and Scully [21]. These studies have been limited to two-input models and have been estimated with restrictive functional forms. By contrast this study is unique in that it expands the analysis to three inputs by adding energy to the typical capital-labor model and estimates the cost function using a flexible functional form.

The translog cost model, a flexible functional form for estimating the general cost function, was selected to estimate the three-input model because it imposes no a priori restrictions on the elasticities, and it can be viewed as a second order approximation to any arbitrary twice-differentiable cost function. National studies of input interrelations using the translog cost model have been done by Hudson and Jorgenson [17], Berndt and Wood [6], Griffin and Gregory [16], Pindyck [20], and Field and Grebenstein [14]. The orientation of the following model has benefited from these efforts.

\section{Model}

Given a twice differentiable and regular production structure for U.S. manufacturing by state, then the dual cost function exists which describes uniquely that underlying technology. ${ }^{1}$ Furthermore, assuming constant returns to scale and weak separability of the materials input from all other imputs, allows the modelling to proceed without inclusion of output and price of materials. The latter assumption is necessitated by the lack of cross-sectional data on the heterogeneous input materials, while the former assumption of constant returns to scale is well-established in the literature. ${ }^{2}$ Then, the dual cost function can be expressed as

(1) $\mathbf{C}=\mathbf{C}\left(\mathbf{P}_{\mathrm{K}}, \mathrm{P}_{\mathrm{L}}, \mathrm{P}_{\mathrm{E}}\right)$

where $C$ is unit cost, $P_{K}$ is the price of capital, $P_{L}$ 
is the price of labor, and $P_{E}$ is the price of energy. The advantage of (1) over direct estimation of the production structure is that input prices are more readily observable and likely exogenous than input quantities, while duality theory insures that conclusions about (1) apply equally well to the underlying production structure.

The flexible translog functional form, introduced by Christensen, Jorgenson, and Lau [9], where

(2) $1 n C=\alpha_{o}+\Sigma \alpha_{i} \ln P_{i}+\frac{1}{2} \underset{i j}{\sum \Sigma} \gamma_{i j} \ln P_{i} \ln P_{j} \quad i, j=K, L, E$

with constraints ${ }^{3} \sum \alpha_{i}=1,{ }_{j} \gamma_{i j}=0, \underset{j}{\gamma_{i j}}=0$, and $\gamma_{i j}=\gamma_{j i}, \quad i \neq j$, is chosen to represent the general cost function in (1) because it imposes no $a$ priori restrictions on the price and Allen elasticities and because it can be viewed as a second order local approximation or Taylor series expansion in logarithms to any cost function. ${ }^{4}$ In short, the translog approximation appears well-suited for determining the KLE interrelationships in U.S. manufacturing. ${ }^{5}$

Logarithmic differentiation of (2) with respect to input prices and application of Shephard's lemma [22, p. 11] yields the share equations $\left(M_{i}\right)$ to be estimated,

(3) $\frac{\partial 1 \mathrm{nC}}{\partial 1 \mathrm{nP}}=\frac{\partial \mathrm{C}}{\partial \mathrm{P}_{\mathrm{i}}}=\frac{\mathrm{P}_{\mathrm{i}}}{\mathrm{C}}=\frac{\mathrm{P}_{\mathrm{i}} \mathrm{q}_{\mathrm{i}}=}{\sum_{\mathrm{i}} \mathrm{P}_{\mathrm{i}} \mathrm{q}_{\mathrm{i}}}$ $\mathrm{M}_{\mathrm{i}}=\alpha_{\mathrm{i}}+\sum_{\mathrm{j}} \gamma_{\mathrm{ij}} \mathbf{l n P}_{\mathrm{j}}{ }_{\mathrm{i}} \mathrm{P}_{\mathrm{i}} \mathrm{q}_{\mathrm{i}} \quad \mathrm{i}, \mathrm{j}=\mathrm{K}, \mathrm{L}, \mathrm{E}$

Since both the existence of the dual cost function and the validity of Shephard's lemma requires regularity of the production structure, that aspect of the specification is tested. The translog approximation is monotonic if the fitted cost shares are positive at each data point, and it is quasi-concave if the matrix of estimated Allen elasticities is negative semidefinite at the point of expansion, the means of the data.

The stochastic specification of the model in (3) is completed by appending additive error terms representing random errors in cost minimizing behavior to the share equations. It is assumed that these error terms are randomly distributed within equations, although crossequation correlation is likely since errors in cost minimizing behavior should affect all cost shares. Since the system of equations in (3) is singular, one equation is deleted, and the iterative Zellner procedure is then appropriate to

obtain asymptotically efficient parameter estimates equivalent to maximum likelihood methods. ${ }^{6}$

The $\mathbf{K}, \mathbf{L}$, and $\mathbf{E}$ interrelations are summarized by the estimated price $\left(\mathrm{E}_{\mathrm{ij}}\right)$ and Allen $\left(\sigma_{i j}\right)$ elasticities, where for the translog case these are given in terms of the cost shares and parameter estimates as,

(4)

$$
\begin{aligned}
& \mathbf{E}_{\mathrm{ii}}=\frac{\hat{\mathbf{M}}_{\mathrm{i}}{ }^{2}-\hat{\mathbf{M}}_{\mathrm{i}}+\gamma_{\mathrm{ii}}}{\hat{\mathbf{M}}_{\mathrm{i}}} \\
& \mathbf{E}_{\mathrm{ij}}=\frac{\hat{\mathbf{M}}_{\mathrm{i}} \hat{\mathbf{M}}_{\mathrm{i}}+\gamma_{\mathrm{ii}}}{\mathbf{M}_{\mathrm{i}}}
\end{aligned}
$$

and

$$
\text { (5) } \begin{array}{rlrl}
\sigma_{i i} & =\frac{\hat{\mathbf{E}}_{\mathrm{ii}}}{\hat{\mathbf{M}}_{\mathrm{i}}}=\frac{\hat{\mathbf{M}}_{\mathrm{i}}-\hat{\mathbf{M}}_{\mathrm{i}}+\gamma_{\mathrm{ii}}}{\hat{\mathbf{M}}_{\mathrm{i}}} & \mathbf{I}=\mathbf{K}, \mathrm{L}, \mathbf{E} \\
\sigma_{\mathrm{ij}}=\frac{\hat{\mathrm{E}}_{\mathrm{ij}}}{\hat{\mathbf{M}}_{\mathrm{j}}}=\frac{\hat{\mathbf{M}}_{\mathrm{i}} \hat{\mathbf{M}}_{\mathrm{i}}+\gamma_{\mathrm{ii}} \bullet \hat{\mathbf{M}}_{\mathrm{i}}}{\hat{\mathbf{M}}_{\mathrm{i}}} & \mathrm{ij}=\mathbf{K}, \mathrm{L}, \mathrm{E} \quad \mathrm{i} \neq \mathbf{j}
\end{array}
$$

\section{Model Implementation}

The model is estimated for U.S. manufacturing using cross-sectional data by state for 1976 . The required data on the prices and cost shares of capital, labor, and energy respectively were obtained primarily from the Annual Survey of Manufacturers [23]. The price of energy is computed as total cost for energy divided by gross millions of BTUs consumed. The price of labor per man-hour is computed as total labor costs, including supplementary benefits, divided by total man-hours worked. Since data on manhours worked is not provided for non-production workers, it is assumed that one man-year for each non-production worker equals 2,000 hours.

The price of capital was constructed following the approach of Christensen and Jorgenson [8], while the quantity of capital, structures and equipment for each state was estimated using the perpetual inventory method. The contribution of capital in total cost is its price multiplied by the quantity of capital. For a more detailed explanation of the methodology for the construction of the price and quantity of capital, see the appendix.

As stated earlier, past research has indicated that broad regional differences exist within the U.S., especially noticeable between the North and South. If so, the model in (3) will not capture these differences, yet they remain significant in determining the cost shares for each state. The broad four region Census Bureau 
classification was used to specify four regional dummy variables deleting Alaska, Hawaii, and the District of Columbia. ${ }^{7}$

First order variation in the coefficients of the translog cost function allows the intercepts $\left(\alpha_{i}\right)$ of the share equations to vary between the regions, while second order variation allows the slope parameters $\left(\gamma_{\mathrm{ij}}\right)$ of the share equations to vary between the regions. Null hypotheses of equality of the first order coefficients and second order coefficients within the input shares can then be tested using the approach suggested by Christensen, Jorgenson, and Lau [9] for linear restrictions in the translog case. Equality of the first order or second order coefficients econometrically amounts to a simultaneous test across the input cost shares that the differential intercept or slope coefficients for the regions are zero. Acceptance of both first and second order variation implies that the production structures of the regions should be modelled separately.

\section{Empirical Results}

The regional dummy variables are evaluated first. The empirical tests of hypotheses for first order regional variation in the parameter estimates of the translog cost function are reported in Table 1. First order North-South, MidwestSouth, and West-South variation is accepted, while equality of the North-Midwest and the North-West pairs cannot be rejected. These results suggest that the South is statistically different from the North, Midwest, and West, while the North is not statistically different from the Midwest and West.

After combining the states of the Midwest and West with the North, second order variation is tested and decisively rejected $[\mathrm{F}(6,85)=$

TABLE 1

Tests of Hypotheses of First Order Regional Variation in the Parameter Estimates of the Three-Input Translog Cost Function for North, South, Midwest and West

\begin{tabular}{lccc}
\hline \multicolumn{1}{c}{$\begin{array}{c}\text { First Order } \\
\begin{array}{c}\text { Equality } \\
\text { Tested (share } \\
\text { intercepts) }\end{array}\end{array}$} & $\begin{array}{c}\text { Degrees } \\
\text { of } \\
\text { Freedom }\end{array}$ & Calculated F & $\begin{array}{c}\text { Critical F } \\
(.05)\end{array}$ \\
\hline North = South & 2,85 & 5.1564 & 3.12 \\
North = Midwest & 2,85 & .6081 & 3.12 \\
North = West & 2,85 & 1.1363 & 3.12 \\
Midwest = South & 2,85 & 11.8192 & 3.12 \\
West = South & 2,85 & 4.0419 & 3.12 \\
\hline
\end{tabular}

$.97>$ Prob $(F>.97)=.45]$. It is also noted that in the same model, first order North-South variation is tested and strongly accepted $[\mathrm{F}(2,89)$ $=10.92, \operatorname{Prob}(F>10.92)=.0001]$. Thus, the preferred model is one in which the first order parameters of the translog cost function are allowed to vary between the North and South. ${ }^{8}$

The parameter estimates and associated standard errors of the preferred model with first order North-South variation are presented in Table 2. The price and Allen elasticities of the means of the data and their approximate standard errors following Pindyck [20, p. 171] are presented in Tables 3 and 4 . Though not reported in detail here, it is noted that the aggregate cost function estimated without first order dummies resulted in less precise, but essentially similar second order parameter estimates.

TABLE 2

Translog Cost Function Parameter Estimates, U.S. Manufacturing, 1976

\begin{tabular}{|c|c|}
\hline Parameter & $\begin{array}{c}\text { U.S. } \\
\text { Manufacturing }\end{array}$ \\
\hline$\alpha_{K}$ & $\begin{array}{l}.165600) \\
(.005455\end{array}$ \\
\hline$\alpha_{L}$ & $\begin{array}{l}.756640) \\
(.008603\end{array}$ \\
\hline$\alpha_{\mathrm{E}}$ & $\begin{array}{l}.077760) \\
(.004585\end{array}$ \\
\hline $\mathbf{D}_{\mathrm{K}}$ & $\begin{array}{l}.019400) \\
(.009271\end{array}$ \\
\hline $\mathrm{D}_{\mathrm{L}}$ & $\begin{array}{c}-.060334) \\
(.014729\end{array}$ \\
\hline $\mathrm{D}_{\mathrm{E}}$ & $\begin{array}{l}.040934) \\
(.007875\end{array}$ \\
\hline$\gamma_{\mathrm{KK}}$ & $\begin{array}{l}.090001) \\
(.019988\end{array}$ \\
\hline$\gamma_{\mathrm{KL}}$ & $\begin{array}{c}-.049746) \\
(.022524\end{array}$ \\
\hline$\gamma_{\mathrm{KE}}$ & $\begin{array}{c}-.040255) \\
(.010788\end{array}$ \\
\hline$\gamma_{\mathrm{LL}}$ & $\begin{array}{r}-.015378^{*} \\
(.033352)\end{array}$ \\
\hline$\gamma_{\mathrm{LE}}$ & $\begin{array}{l}.065124) \\
(.016300\end{array}$ \\
\hline$\gamma_{E E}$ & $\begin{array}{c}-.024869) \\
(.010435\end{array}$ \\
\hline System $R^{2}$ & .3541 \\
\hline $\mathbf{n}$ & 48 \\
\hline
\end{tabular}

*Not statistically significant at the .05 level.

Note: $\alpha_{i}$ are the intercepts for the North, while $D_{i}$ are the South differentials to those intercepts, $i=$ K,L,E. 
TABLE 3

Price Elasticities U.S. Manufacturing North-South, 1976

\begin{tabular}{ccc}
\hline Elasticity & North & South \\
\hline \multirow{2}{*}{$\mathrm{E}_{\mathrm{KK}}$} & $-.302896)$ & -.346208 \\
& $(.116817)$ & $(.101436)$ \\
$\mathrm{E}_{\mathrm{LL}}$ & -.264495 & -.326224 \\
& $(.044125)$ & $(.047927)$ \\
$\mathrm{E}_{\mathrm{EE}}$ & -1.26742 & -1.12522 \\
& $(.142857)$ & $(.097467)$ \\
$\mathrm{E}_{\mathrm{KL}}$ & .465116 & .443433 \\
& $(.131638)$ & $(.114306)$ \\
$\mathrm{E}_{\mathrm{LK}}$ & .105290 & .125564 \\
& $(.029799)$ & $(.032367)$ \\
$\mathrm{E}_{\mathrm{KE}}$ & -.162220 & $-.097226 *$ \\
& $(.063049)$ & $(.054748)$ \\
$\mathrm{E}_{\mathrm{EK}}$ & -.379994 & $-.178947 *$ \\
& $(.147690)$ & $(.100764)$ \\
$\mathrm{E}_{\mathrm{LE}}$ & .159204 & .200646 \\
& $(.021565)$ & $(.023423)$ \\
$\mathrm{E}_{\mathrm{EL}}$ & 1.64741 & 1.30417 \\
& $(.223150)$ & $(.152248)$ \\
\hline
\end{tabular}

*Not statistically significant at the .05 level.

The empirical results of the model indicate that all own-price elasticities are significantly negative. Furthermore, the estimated cost shares are positive at each data point, and the matrix of estimated Allen elasticities at the means of the data is negative semidefinite. Thus, cost minimizing behavior is accepted, and the cost function appears regular.

All parameter estimates of the translog cost function are significant except one. All crossprice and Allen elasticities are significant except one. The K-L and L-E pairs are substitutes, and labor appears more substitutable with energy than capital.

In general, the regional variation in the elasticity estimates are small. However, the striking feature of these elasticity estimates is that capital and energy are strong and statistically significant complements in the North, while they are weak and statistically insignificant complements in the South.

\section{Conclusions}

Using a translog cost function where the inputs are capital, labor, and energy, this study explored the possibility that there are regional differences in production functions. The major finding of the study is that there is significant North-South regional variation in a threeinput model. In terms of elasticity estimates,
TABLE 4

Allen Elasticities U.S. Manufacturing, North-South, 1976

\begin{tabular}{ccc}
\hline Elasticity & North & South \\
\hline $\mathrm{A}_{\mathrm{KK}}$ & -1.77027 & -1.75696 \\
& $(.682722)$ & $(.514774)$ \\
$\mathrm{A}_{\mathrm{LL}}$ & -.349931 & -.468789 \\
& $(.058378)$ & $(.068872)$ \\
$\mathrm{A}_{\mathrm{EE}}$ & -17.3518 & -10.5100 \\
& $(1.95574)$ & $(.910378)$ \\
$\mathrm{A}_{\mathrm{KL}}$ & .615355 & .637220 \\
& $(.174159)$ & $(.164259)$ \\
$\mathrm{A}_{\mathrm{KE}}$ & -2.22082 & $-.908130 *$ \\
& $(.863153)$ & $(.511363)$ \\
$\mathrm{A}_{\mathrm{LE}}$ & 2.17955 & 1.87411 \\
& $(.295231)$ & $(.218783)$ \\
\hline
\end{tabular}

*Not statistically significant at the .05 level.

the most important of these regional differences is that capital and energy tend to be strong and significant complements in the North, while they are weak and insignificant complements in the South. The implication of this result is that rising energy prices may have a more adverse effect on the industries of the North than the South.

The most likely explanation for these observed results is that the North contains a specific mix or concentration of industries where K-E complementarity predominates. Another explanation might be the possibility that the South contains newer capital which tends to be more substitutable for energy than the older capital of the North. Examination of these possibilities and other broad regional differences which may account for these results such as basic regional infrastructure, agglomeration economies, and labor quality may be fruitful avenues for future research.

\section{FOOTNOTES}

${ }^{1}$ For a short, yet complete survey of duality theory, see Diewert [12]

${ }^{2}$ For an excellent discussion of this point, see the survey article by Jorgenson [18]. A slightly different and earlier nonhomothetic specification of the translog cost model in this study allowed for specific testing of homotheticity. If a cost function is not homothetic, then the production structure cannot be one of constant returns to scale. The results of that test strongly supported homotheticity.

3These constraints are minimal in that economic theory indicates that they are applicable to any arbitrary cost function. See Christensen, Jorgenson, and Lau [9] and the more general discussion in R.G.D. Allen [1, pp. 503-509].

4The properties of the translog approximation are developed by Denny and Fuss [11].

${ }^{5}$ Recently Berndt, Darrough, and Diewert [5] examined three flexible function forms applied to Canadian consumer 
demand functions. Their conclusion was that the translog functional form was preferable on theoretical and econometric grounds for the specific data set examined.

'See Zellner [25] for the development of his original "seemingly unrelated regression" method and Kmenta-Gilbert [19] for the properties of the iterative Zellner procedure.

${ }^{7}$ The broad four region Census Bureau classification was used as follows: North = ME, NH, VT, MA, RI, CT, NY, NJ, PA; Midwest $=$ OH, IN, IL, MI, WI, MN, IA, MO, ND, SD, NE, KS; South = DE, MD, VA, WV, NC, SC, GA, FL, KY, TN, AL, MS, AR, LA, OK, TX; West = MT, ID, WY, CO, NM, AZ, VT, NV, WA, OR, CA.

${ }^{8}$ In an earlier and slightly different version of the model in this study, various tests of hypotheses were accomplished using nine regional dummy variables. However, no other regional variation besides the North-South dichotomy were even remotely statistically acceptable.

\section{REFERENCES}

1. Allen, R.G.D. Mathematical Analysis for Economists. New York: Macmillan Co., 1938.

2. Batra, R. and G. W. Scully. "Technical Progress, Economic Growth, and the North-South Wage Differential," Journal of Regional Science, 12 (1972), 375-386.

3. Bellante, R. "The North-South Differential and the Migration of Heterogeneous Labor," American Economic Review, 69 (1979), 166-175.

4. Berndt, E. R. and L. R. Christensen. "The Translog Function and the Substitution of Equipment, Structures, and Labor in U.S. Manufacturing, 1929-1968," Journal of Econometrics, 1 (1973), 81-114.

5. — M. N. Darrough, and W. E. Diewert. "Flexible Functional Forms and Expenditure Distributions: An Application to Canadian Consumer Demand Functions," International Economic Review, 18 (1977), 651675.

6. Derived Demand for Energy," Review of Economics and Statistics, 57 (1975), 259-268.

7. tions of Energy-Capital Complementarity," American Economic Review, 69 (1979), 342-354.

8. Christensen, L. R. and D. W. Jorgenson. "The Measurement of U.S. Real Capital Input, 1929-1967," Review of Income and Wealth, (1969), 293-319.

9. — and L. J. Lau. "Transcendental Logarithmic
Production Frontiers," Review of Economics and Statistics, 5 (1973), 28-45.

10. Coelho, P.R.P. and M. A. Ghali. "The End of the NorthSouth Wage Differential,"American Economic Review, 61 (1971), 932-937.

11. Denny, M. and M. Fuss. "The Use of Approximation Analysis to Test for Separability and the Existence of Consistent Aggregates," American Economic Review, 67 (1977), 404-418.

12. Diewert, W. E. "Applications of Duality Theory," in M. D. Intriligator and D. A. Kendrick (eds.), Frontiers of Quantitative Economics, Vol. 11, Amsterdam: NorthHolland Publishing Co., 1974.

13. Federal Deposit Insurance Corporation. Bank Operating Statistics, 1976.

14. Field, B. C. and C. Grebenstein. "Capital-Energy Substitution in U.S. Manufacturing," Review of Economics and Statistics, 62 (1980), 207-212.

15. Gallaway, L. "The North-South Wage Differential," Reivew of Economics and Statistics, 45 (1963), 264-272.

16. Griffin, J. M. and P. R. Gregory. "An Intercountry Translog Model of Energy Substitution Responses," American Economic Review, 66 (1976), 845-857.

17. Hudson, E. A. and D. W. Jorgenson. "U.S. Energy Policy and Economic Growth, 1975-2000," Bell Journal of Economics, 5 (1974), 461-514.

18. Jorgenson, D. W. "Investment and Production: A Review," in M. D. Intriligator and D. A. Kendrick (eds.), Frontiers of Quantitative Economics, Vol. III, Amsterdam: North-Holland Publishing Co., 1974.

19. Kmenta, J. and R. Gilbert. "Small Sample Properties of Alternative Estimators of Seemingly Unrelated Regressions," Journal of the American Statistical Association, 63 (1968), 1180-2000.

20. Pindyck, Robert S. "Interfuel Substitution and the Industrial Demand for Energy: An International Comparison," Review of Economics and Statistics, 61 (1979), 169-179.

21. Scully, G. W. "The North-South Manufacturing Wage Differential 1869-1919," Journal of Regional Science, 11 (1971), 235-252.

22. Shephard, R. W. Cost and Production Functions. Princeton: Princeton University Press, 1953.

23. U.S. Department of Commerce, Bureau of Census. Annual Survey of Manufacturers, various issues.

24. U.S. Department of Commerce, Bureau of Census. Census of Manufacturers, 1958.

25. Zellner, A. "An Efficient Method of Estimating Seemingly Unrelated Regressions and Tests for Aggregation Bias," Journal of the American Statistical Association, 57 (1962), 348-368. 


\section{Appendix}

For each state the quantity of capital, structures and equipment is estimated using the perpetual inventory method where

$$
\mathrm{K}_{\mathrm{ts}}=\mathrm{PI}_{\mathrm{t}} \mathrm{I}_{\mathrm{ts}}+(\mathrm{I}-\mathrm{d}) \mathrm{K}_{\mathrm{ts}-1}
$$

and

$$
\begin{aligned}
\mathbf{K}_{\mathrm{ts}}= & \text { capital stock in year } \mathrm{t} \text { and state } \mathrm{s} \\
\mathrm{PI}_{\mathbf{t}}= & \text { price index for structures and equip- } \\
& \text { ment in year } \mathrm{t} \\
\mathrm{I}_{\mathrm{ts}}= & \text { capital expenditures for structures } \\
& \text { and equipment in year } \mathrm{t} \text { and state } \mathrm{s} \\
\mathrm{d}= & \text { average replacement rate for struc- } \\
& \text { tures and equipment }
\end{aligned}
$$

The base year to begin the capital stock calculations was 1958 because of the complete capital stock information available in Census of Manufactures [24]. The price index, $\mathrm{PI}_{t}$, was set equal to 1.0 in 1976 . The average replacement rate, $d$, was estimated as the mean rate implicit in the aggregate capital stock estimates for U.S. manufacturing, 1958-76, following
Berndt-Christensen [4]. The estimated replacement rate was .1085 with a standard error of .0025 .

The service or rental price of capital was constructed following the approach of Christensen and Jorgenson [8] as:

$$
P_{K s}=\left[\frac{1-T_{s} P V_{s}}{1-T_{s}}\right]\left[P_{75} r_{s}+d-\left(1-P_{75}\right)\right]
$$

where

$$
\begin{aligned}
P_{\mathrm{K}_{\mathrm{B}}}= & \text { price of capital in state } \mathrm{s} \\
\mathrm{T}_{\mathrm{B}}= & \text { effective corporate tax rate in state } \mathrm{s} \\
\mathbf{r}_{\mathrm{B}}= & \text { cost of capital in state } \mathrm{s} \\
\mathrm{PV}_{\mathrm{s}}= & \text { present value of depreciation deduc- } \\
& \text { tion on one dollar's worth of invest- } \\
& \text { ment in state } \mathrm{s}
\end{aligned}
$$

The effective corporate tax rate was computed following Field-Grebenstein [14]. The cost of capital was assumed equal to the gross return on total loans in state $\mathbf{s}$ as found in Federal Deposit Insurance Corporation [13]. The present value of one dollar's worth of investment in state $\mathrm{s}$ was computed assuming sum-of-the-digits depreciation method. 